\title{
The University of Iowa Center for the Book
}

\author{
D A V I D E. S C H O O N O V E R
}

In June 1986 Iowa's State Board of Regents declared its formal approval for establishing the Iowa Center for the Book. During the past year many activities related to the center have occurred: exhibitions, lectures, courses, workshops, meetings, and publications. This article, prepared with the assistance of staff and faculty connected to the Iowa Center for the Book, relates the center's history, explains its purposes, and presents some of its accomplishments.

It must be emphasized here that the word book in the center's title is used as a paradigm. While "the book" as normally thought of is the core of the center's activities, the word itself is intended to cover every aspect of written or printed communication, in terms of physical development and cultural importance, since the invention of the book itself. The history of manuscripts, the development of periodicals, the function of graphic designers - these areas, among many others, would be covered by it. Consequently, where the word book is encountered in the following pages, it should be read with this broad definition in mind.

Although printing courses had been taught at Iowa since the late 1930s, serious typographic studies began in 1945 when Wilbur Schramm, then director of the School of Journalism, received a major grant from T. Henry Foster, an Iowa business man and bibliophile, to create a Typography Laboratory in the University's new Communications Center. With the establishment of the Type Lab, the School of Journalism and Mass Communication began a long-standing commitment to the support of creative activity related to books and printing. This commitment provided a cornerstone for the foundation of the

All photographs for this article were taken by Jon Van Allen and are used through the courtesy of The University of Iowa Foundation. 
Iowa Center for the Book and remains an important element of the center's academic dimension.

In the Typography Laboratory students could learn both the history and practice of printing. When Carroll Coleman, founder of the Prairie Press, was appointed as the lab's first director, he not only established courses that are still being taught but he trained many students who went on to eminent careers in scholarly editing, academic and trade publishing, and other related fields. Harry Duncan, whose Cummington Press had issued some of the most important books of the preceding 20 years, succeeded Coleman in 1956. Since 1971 Kay Amert, proprietor of the Seamark Press, has directed the laboratory, continuing the tradition of practicing what she teaches.

The School of Journalism and Mass Communication also provides facilities for computerized editing and typesetting, photography, and other activities related to books and printing. Through such courses as Graphic Design and Production, Introduction to Typography, and The History of the Book, students become engaged in both creative work and in critical writing about design. In the lab students may design, typeset, print, and bind projects of their own choosing. They may complement their production work by studying The History of the Book, where they are introduced to the basic literature in this field.

The Typography Laboratory, the only facility of its kind in the country, soon became an important factor in the resurgence of fine printing and small press publishing in the United States. To capitalize on its success and to add new opportunities for study the University established, in 1967, the Windhover Press, the first fine press to be an official part of a university community. Directed by Kim Merker, the press serves as a publishing arm of the University, issuing limited editions of original work having literary or historical importance. Merker's courses allow students to act as apprentices as well as scholars, gaining professional experience not only in traditional letterpress printing methods but in all aspects of publishing as well. In recent years several other universities and colleges have started presses based on the Windhover model. It is difficult to 
estimate the number of fine presses or small publishing firms established by individuals who were students at the Typography Laboratory and/or the Windhover Press, but more than a dozen have achieved national prominence in the field.

In the 1950s, both here and abroad, scholars from many disciplines began investigating the relation between the invention of printing and the development of modern society. Relying heavily on this new research, as well as the traditional printing history of the past, Merker and Amert revived, in 1980, the course The History of the Book. It had not been taught for a number of years, though it had previously been

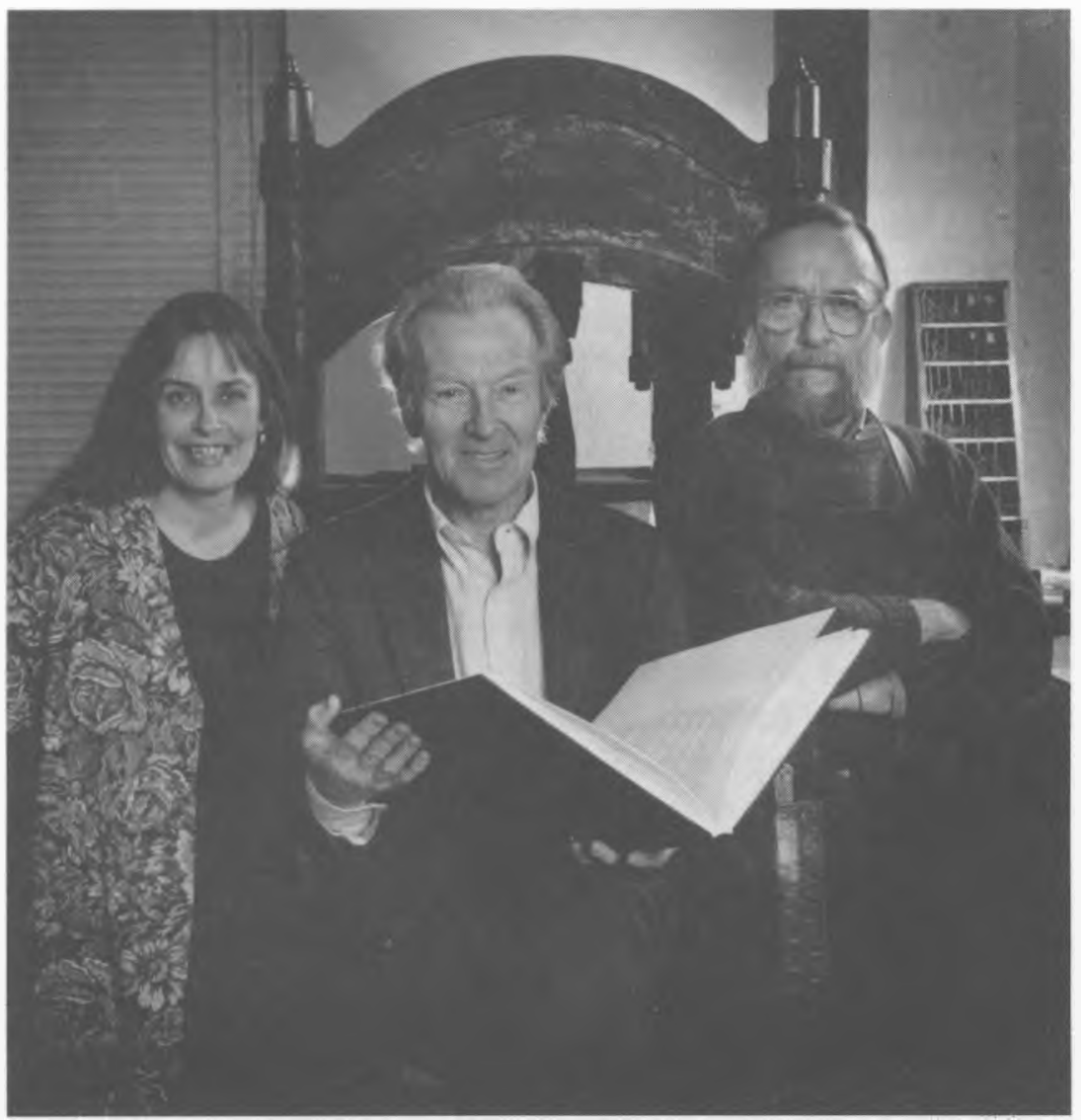

Left to right: Kay Amert, William Anthony (holding a copy of Samuel Beckett's Company), and Kim Merker. 
offered by both the School of Library Science and the School of Journalism and Mass Communication. Student response to this academic material was as strong as it had been to the more practical matters taught at the Typography Laboratory and the Windhover Press. This interest resulted in the idea of an Iowa Center for the Book. With its unique physical facilities already in place and a strong interdisciplinary interest in the history, function, and creation of the book, The University of Iowa had the potential for becoming the only academic institution in the country where the book in all its manifestations could be studied seriously.

For this potential to be realized, the existing facilities needed to be expanded. With money raised from individuals and private foundations and with the help of the Graduate College, the School of Art and Art History, and the University Libraries, the University established a new student bindery and printing studio, a teaching facility for papermaking in the Art Building, a production paper mill at the Oakdale Campus, and a conservation studio and bindery in the Main Library. The Graduate College added new offset printing equipment to the photography area of the School of Art and Art History, permitting professional book work in that medium to be done under the direction of Associate Professor James Snitzer.

In 1984 William Anthony, a major figure in the disciplines of book conservation and fine binding, was appointed University conservator. As an extension of his professional duties in the library he, with the aid of an apprentice, established courses in beginning and advanced bookbinding. In 1985 Timothy Barrett, an expert in both Western and Oriental papermaking techniques, was appointed to teach courses in these areas and to direct the production papermaking facility. Then in 1986 the University Libraries appointed David Schoonover as curator of rare books, with responsibility for continuing a wide range of acquisitions for the Special Collections Department that would enhance and support many of the center's activities. Finally, Glen Epstein, a professional calligrapher, received an adjunct appointment in the School of Art and Art History so that he could teach beginning and advanced courses in this field through the Saturday and Evening Class Program. 
The University of Iowa Center for the Book has been created to advance knowledge about the book and to encourage all of the arts and crafts related to it. To accomplish these purposes, it will pursue the following goals.

1) The center will develop an interdisciplinary program of teaching in fields related to the book. The College of Liberal Arts already offers more than a dozen relevant courses, and faculty throughout the college will be encouraged to create new ones where the development of the book intersects with the content of their specific disciplines. Such courses may include Issues in Contemporary Critical Theory: Orality and Literacy (Spring 1987) and Editing a Literary Journal: New Directions Publishing, 1936-1986 (Spring 1988), both offered in the English department, and The Underground Press in Eighteenth Century France, in the history department. These courses will be cross-listed as appropriate and departments will be asked to permit their students to have formal cross-learning experiences in their undergraduate majors or in their graduate programs. In the future, but only if fully warranted by student interest, the center may apply to the University to offer an undergraduate certificate program, or a Master's degree, of its own.

2) The center will encourage scientific and humanistic research on the book through traditional patterns of scholarly inquiry, by creating new knowledge about the book, and by defining new areas for future research. While the center's faculty and staff are already engaged in this, others will be encouraged to pursue these areas of research. To this end, the center will actively seek grants, both for individual projects as well as larger, interdisciplinary ones. Additionally, the center will seek opportunities and funding for interinstitutional programs involving universities, museums, and public and private libraries.

3) The center will facilitate the professional practice of bookrelated arts and crafts by preserving traditional techniques and practices; developing new applications of these traditions; and fostering the creation and invention of original materials, techniques, and artifacts. This creative work, already occurring in the center's laboratories, presses, and studios, is exemplified in Samuel Beckett's Company, published by the Iowa Center for the Book in 52 signed and numbered copies, with 13 etchings by Dellas Henke, printed at the Windhover Press and bound by William Anthony. In the future the center will bring visiting artists, designers, typographers, printers, papermakers, and binders to campus in order to enrich the ongoing activities. During 1987-88 the University's Ida Beam Distinguished Visiting 
Professorship will include Donald Lamm, president of W. W. Norton \& Company, and printing historian John Dreyfus.

4) An important facet of the center's activities will be the training of academic researchers and artistic specialists. The goal is to provide society with trained individuals who can solve future intellectual and practical problems associated with the book. Graduate students in art, English, journalism, history, and in librarianship already are dealing with these matters, if sometimes only tangentially. More integrated learning opportunities are being explored, and new programs-in book preservation, for instance-and new apprenticeships in papermaking and in printing are being considered.

5) The center will disseminate knowledge about the book through lectures, symposia, conferences, workshops, exhibitions, and publications. In addition to the present account, three other articles on the center have appeared recently. In the June/July 1987 issue of American Craft, W. Thomas Taylor described the center's genesis, current acțivities, and goals. The University of Iowa Foundation's "Twentieth Annual Report of the Presidents Club and the Presidents Club Associates" [1987] and "Rave 1987" have featured handsomely illustrated accounts of the center's arts.

The center also exchanges information with outside individuals and institutions which are active in the field, informs the general public about its work, and promotes its interests by seeking national and international visibility for diverse activities. The faculty and staff associated with the center have given many presentations, both here and abroad, and this will be continued in the future.

6) In collaboration with the University of Iowa Press, the center will seek new manuscripts related to the book for possible publication under the University's imprint. It will also propose important works, some of which have long been out of print, for possible reissue. A national board of editors, operating under the center's auspices, will make the selections. No work will be published, however, unless it meets the editorial standards established by the press. Those titles that are accepted will be issued as part of an Iowa Center for the Book series, and information to this effect will appear on the title pages.

7) The final goal will be building and maintaining an environment at The University of Iowa which will allow the scholarly interest in the book and the practice of book-related arts and crafts to flourish. This can be done partly by creating an atmosphere of collegiality and broad cooperation. The center's 
colleagues have established monthly meetings and made plans to involve additional faculty, staff, and students in their projects.

In pursuing its goals, the Iowa Center for the Book is striving to create a spirit of cooperation and participation among many elements of a large research institution: University libraries, schools, departments, programs, faculty, staff, students, and interested citizens.

Within the libraries, the Special Collections Department has acquired, through gift and purchase, a range of books and archives to support research in printing, bookbinding, papermaking, and private presses. In 1936 John Springer, an Iowa City advertising agent, newspaper editor, and printer, gave the University the most extensive library on printing in the state. The Springer Collection on Typography contained more than 2,300 volumes, including type specimens, histories of printing, and advertising information on presses, types, paper, and other equipment. Then in 1951 the Typography Laboratory's benefactor, $\mathrm{T}$. Henry Foster, made a bequest of more than 350 books on printing.

The University's rare book collection, traditionally including the work of fine printers, features representative products of more than 100 presses, demonstrating a remarkable variety of techniques, materials, and content. The department is currently receiving archives from Allan Kornblum's Toothpaste and Coffee House Presses and from Charlotte Smith's Tamazunchale Press. These records will provide opportunities for researchers to investigate the operations of three very different printing ventures. The center's programs will be valuable in both increasing the study of these existing materials and in encouraging new acquisitions. For example, the Guild of Bookworkers has recently reached an agreement with The University of Iowa Libraries to place its extensive research collection on permanent loan, to be located in Special Collections. The Center for the Book and the University Libraries, sharing fundamental interests in the book as object and as subject for study, can and should provide mutual support for their endeavors.

University staff and faculty, in association with the center, 
are employing a variety of complementary talents, research interests, and teaching programs to carry out the center's goals. University conservator William Anthony takes equal pride in passing his master's craftsmanship to new practitioners and in demonstrating that mastery by creating a historically accurate medieval binding, in full maroon goatskin, for such a treasure as the library's Liber Chronicarum (1493), better known as the "Nuremberg Chronicle." Anthony's apprentices and other students prepare historical binding models in order to understand the evolution of book structures, then apply that understanding to their treatment of books from the Special Collections Department. This program combines historical practice and analysis with contemporary applications to create unique opportunities for understanding the complexities of bookmaking.

Timothy Barrett is involved in a papermaking program consisting of two areas: teaching and production/research. Students begin with an introductory course in traditional Eastern and Western papermaking techniques. In another semester students may take an advanced class in traditional techniques with Barrett or a paper-pulp-as-media paperworks course with printmaker and paper artist Robert Glasgow. These courses are offered in the School of Art and Art History but carry interdisciplinary numbers and appeal to students from many areas of the University.

Production and research in papermaking take place under Barrett's direction at the Oakdale Campus in a 2,200-squarefoot building housing a wide variety of equipment for papermaking, including two vats, a 200-ton press, three beaters, and five paper moulds. At this facility, Barrett has been investigating the techniques used to make higher quality early European book papers, with the expectation of adapting some of these methods to modern production. He plans to develop papers appropriate for conservators and artists and to provide information about techniques and tools that will benefit the specialized papermaking community at large.

James Snitzer has been involved with artists' publishing projects for the last ten years. In 1976 he co-founded Chicago Books, an offset printing workshop designed to provide individual artists with the opportunity to create specialized pub- 


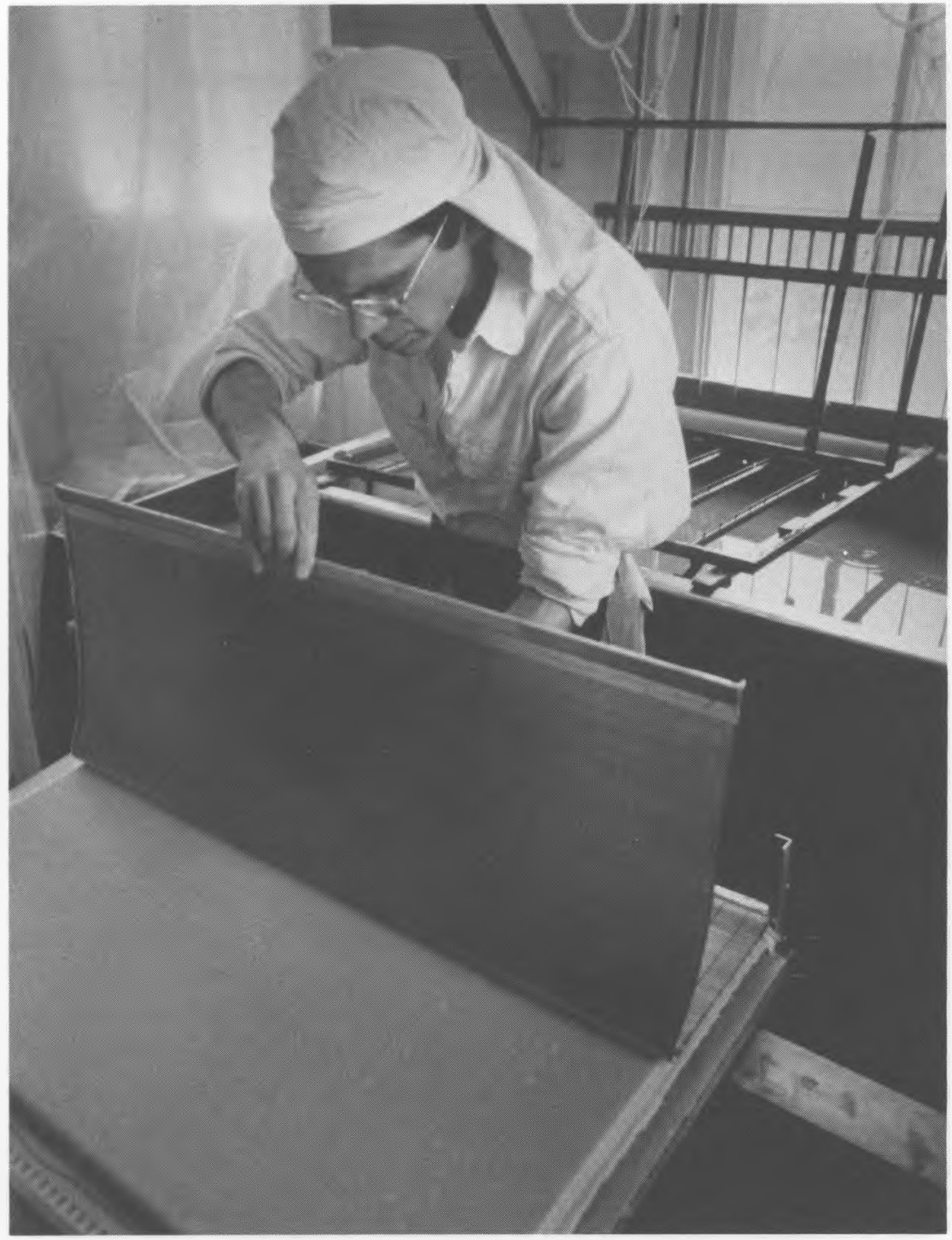

Timothy Barrett couching a sheet of Japanese paper. 


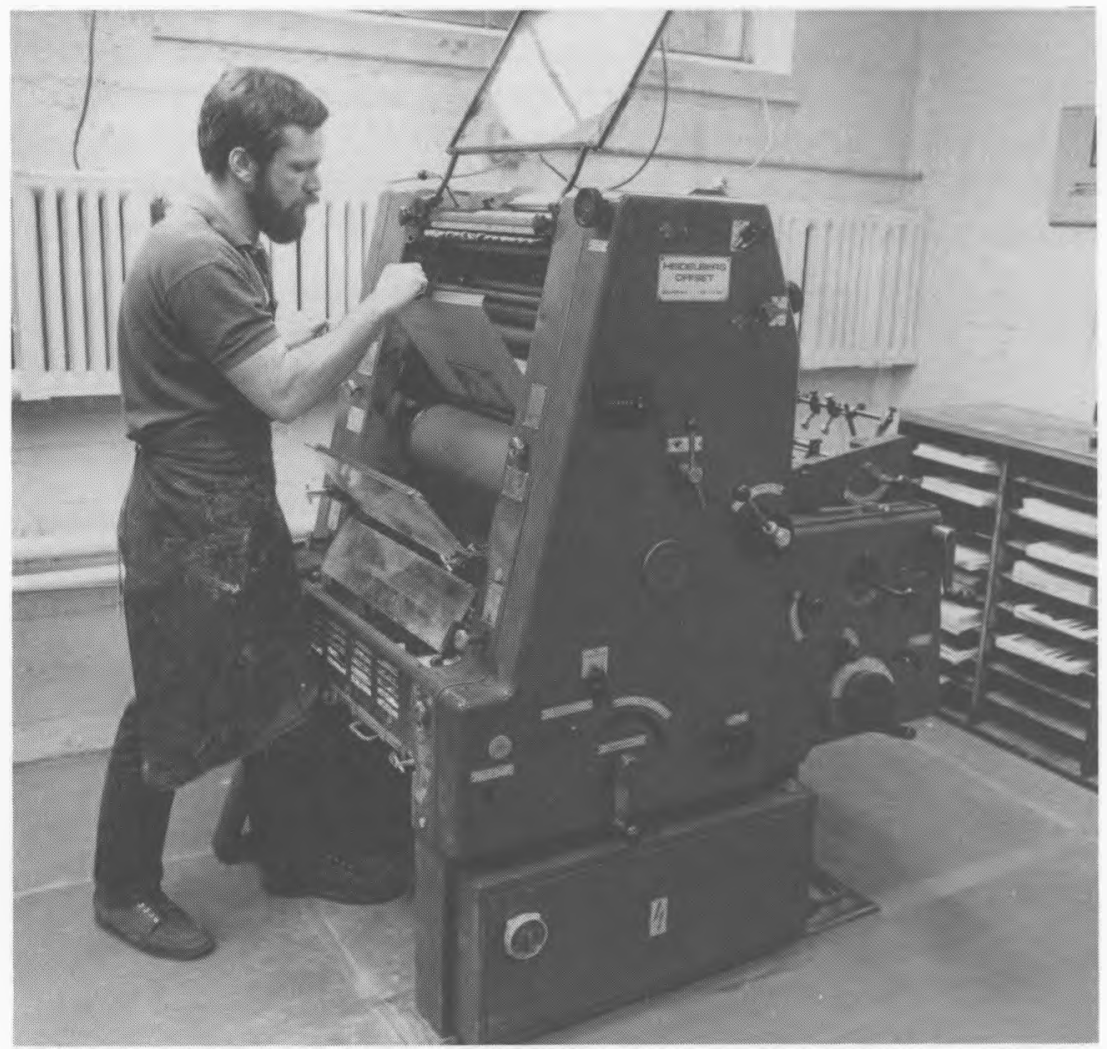

James Snitzer at the Heidelberg offset press.

lishing projects. His intentions were to educate artists about the potential of offset printing technology, beyond its ability to merely reproduce work from another medium. He seeks to extend to the artist a control over all aspects of production, creating uniquely conceived artworks, done in multiple copies, designed specifically for presentation in book format. Chicago Books remains an alternative to conventional publishers by maintaining a climate of collaboration with artists throughout the production process. Their projects, created with painters, photographers, filmmakers, and video and performance artists, represent a diverse range of intentions and sensibilities. Snitzer's hope is to be able to maintain a similar workshop here at Iowa. While continuing his teaching, he is currently prepar- 
ing a book with Byron Burford and is developing projects with Michael Meyers and Robert Peters, both performance artists from Chicago.

As the center has encouraged parallel emphases on craft and scholarship, faculty members are developing and teaching several courses with its existence and interests specifically in mind. Professor Donald G. Marshall recently completed Issues in Contemporary Critical Theory: Orality and Literacy, exploring the transition from oral literature to written culture, from manuscript to printed book, and the influences that these developments had on authors, readers, and literary works. Marshall's course, The Culture of Eighteenth-century England, focuses on the emergence of a large reading audience, the concurrent rise of broad-based commercial printing, and resulting issues of authorship and readership. Marshall is enthusiastic about these experiences: "The issues and approaches I've learned will certainly have a significant impact on all the teaching I do, and I hope I'll have a chance in the future to teach additional courses specifically connected to these topics."

David Schoonover, to be appointed adjunct lecturer in the Department of English for spring 1988, has planned a completely new course. Editing a Literary Journal: New Directions Publishing, 1936-86 will explore the extraordinary impact that James Laughlin's New Directions Publishing Corporation has had in developing modern literature during the last half century. Such a course should attract students interested in literary history, the business of publishing, and the formation of literary tastes and movements.

In announcing the Regents' approval for the center, University President James O. Freedman stated: "The Center for the Book grows naturally out of the University's long heritage of interest in literature and the book. . . . We see interdisciplinary studies frequently in the sciences; here we see it between people whose interests are art, writing, literature, journalism, printing, papermaking, graphics, and other disciplines. It is an enterprise not only in the production of the book, but in its history and in the role that books, both mass-produced and elegantly produced, have played in society." 


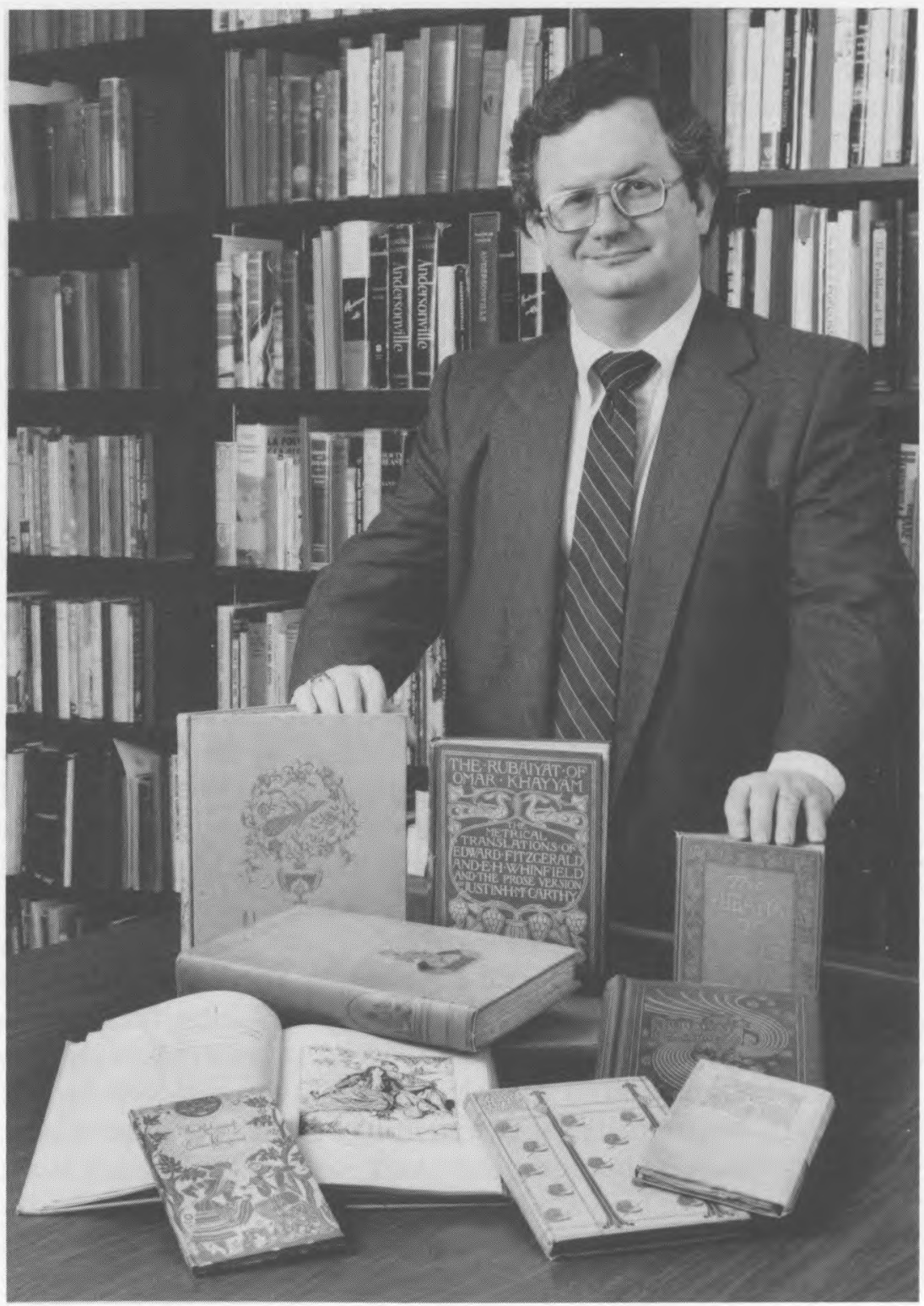

David Schoonover with editions of Omar Khayyâm's Rubáiyát. 